\title{
A PERFORMANCE DO UNIVERSO COMUNICACIONAL NA PUBLICIDADE IMPRESSA DE UMUARAMA/PR EM CINCO DÉCADAS
}

\author{
Sônia Maria Moro do Nascimento ${ }^{1}$ \\ Keila Cristine Cerozino ${ }^{2}$ \\ Yasmim Thainá Marques Pipino 3
}

NASCIMENTO, S. M. M. do; CEROZINO, K. C.; PIPINO, Y. T. M. A performance do universo comunicacional na publicidade impressa de umuarama/pr em cinco décadas. EDUCERE - Revista da Educação, Umuarama, v. 17, n. 2, p. 291-306, jul./dez. 2017

RESUMO: Esta investigação percorreu as origens da mídia impressa, o jornal, em Umuarama/PR, sob uma perspectiva histórica e também de aspectos da linguagem que se referem à dinâmica da produção discursiva bem como da técnica, com vistas no crescimento e tendências da atividade publicitária para o desenvolvimento local e regional. O estudo centrou-se na análise de exemplares de jornais, desde as primeiras edições no início dos anos 1960 até 2007, a fim de identificar as transformações pelas quais passaram a comunicação publicitária impressa com ênfase nos aspectos verbal e visual da linguagem e seus desdobramentos. O acesso a esse material se deu por meio de visitas e de consultas a alguns acervos públicos e institucionais e também de exemplares de circulação periódica.

PALAVRAS-CHAVE: Anúncios Impressos; Evolução da Comunicação; Linguagem Publicitária; Perfornance Comunicacional; Umuarama/PR.

DOI: $10.25110 /$ educere.v17i2.2017.6603

'Doutora em Comunicação e Semiótica. Docente e pesquisadora da UNIPAR. E-mail: soniamoro@ prof.unipar.br

${ }^{2}$ Graduada em Publicidade e Propaganda da UNIPAR. Bolsita PIBIC 2014 - UNIPAR . E-mail: keilacerozinomkt@gmail.com

${ }^{3}$ Acadêmica do curso de Direito da UNIPAR. Bolsita PIBIC 2015 - UNIPAR. E-mail: yasmiimmarquess@hotmail.com 


\title{
PERFORMANCE OF THE COMMUNICATIONAL UNIVERSE IN FIVE DECADES OF PRINT ADVERTISING IN THE CITY OF UMUARAMA/PR
}

\begin{abstract}
This study traced the origins of print media - the newspaper - in the city of Umuarama/PR from a historical perspective and also assessing the language aspects related to the dynamics of the discursive production as well as the technique, focusing on the growth and the tendencies of advertising for local and regional development. The study focused on the analysis of newspaper sample copies, from the first issues in the early 1960 s to 2007 , in order to identify the modifications print advertising communication has gone through, emphasizing verbal and visual aspects of language and their unfolding. The material was accessed during visits and queries to some public and institutional collections as well as newspaper issues.
\end{abstract}

KEYWORDS: Advertising language; Communicational performance; Evolution of communication; Printed ads; Umuarama/PR.

\section{PERFORMANCE DEL UNIVERSO COMUNICACIONAL EN LA PUBLICIDAD IMPRESA DE UMUARAMA/PR EN CINCO DÉCADAS}

RESUMEN: Esta investigación recorrió los orígenes de los medios impresos, el periódico, en Umuarama / PR desde una perspectiva histórica a aspectos del lenguaje que se refieren a la dinámica de la producción discursiva, así como de la técnica, con vistas al crecimiento y tendencias de la actividad publicitaria para el desarrollo local y regional. El estudio se centró en el análisis de ejemplares de periódicos, desde las primeras ediciones a principios de los años 1960 hasta 2007, a fin de identificar las transformaciones por las que pasaron la comunicación publicitaria impresa, con énfasis en los aspectos verbal y visual del lenguaje y sus desdoblamientos. El acceso a ese material se dio por medio de visitas y de consultas a algunos acervos públicos e institucionales y también de ejemplares de circulación periódica.

PALABRAS CLAVE: Anuncios Impresos; Evolución de la Comunicación; Lenguaje Publicitario; Performance Comunicacional; Umuarama/PR. 


\section{INTRODUÇÃO}

Estudos anteriores já realizados por pesquisadores e acadêmicos da Iniciação Científica da Universidade Paranaense - UNIPAR mostram-se inaugural do ponto de vista científico em relação ao desempenho dos meios de comunicação na cidade de Umuarama (ZANOTTO; RIBEIRO, 2005; NASCIMENTO, 2009; NASCIMENTO; OLIVA, 2011). O foco desses estudos se voltou para o resgate da história dos meios de comunicação em Umuarama/PR. Um deles revelou que o jornal - A Gazeta de Umuarama (1961) - foi a primeira mídia se instalar na cidade de Umuarama/PR seguindo-se do Rádio - Rádio Cultura (1963). Já outro apontou a mídia Revista como um dos meios que mais se desenvolveram entre os anos 2000 a 2010. A revista mais antiga que esses estudos alcançaram foi publicada em junho de 1965 (NASCIMENTO; OLIVA, 2011).

A fundação da cidade de Umuarama/PR ocorreu em 26 de junho de 1955. Nessa década de 1950, com a implantação dos veículos de comunicação nos grandes centros do País, despontava a indústria da comunicação. Nos anos subsequentes, ainda que de forma lenta, essa indústria foi se espalhando pelo interior do Brasil. Em Umuarama, no início da década de 1960 surgem os primeiros veículos de comunicação, o Jornal e o Rádio. Em um artigo intitulado "A evolução da indústria da comunicação e seus meios de produção" se pode conferir a trajetória de implantação dos meios de comunicação nessa cidade (NASCIMENTO, 2009). Esses estudos revelaram o panorama histórico da comunicação em Umuarama/ PR no que se refere à trajetória cronológica de implantação dos meios de comunicação e seus meios de produção.

Para ampliar essas informações, esta investigação focalizou outro viés do amplo campo do universo da comunicação local e regional, que é a dinâmica discursiva dos anúncios publicitários impressos e sua técnica de produção. Foram analisados anúncios veiculados em dois jornais de Umuarama/PR, desde as primeiras publicações, no início da década de 1960 até o ano de 2007, a fim de verificar as transformações ocorridas na comunicação publicitária dessa mídia impressa.

\section{A ORIGEM DA MÍDIA IMPRESSA EM UMUARAMA/PR}


Mídia é um termo aportuguesado do inglês mass media (mídia de massa). Moreira et al (1996, p. 225) definem mídia como "os canais de comunicação impessoal que incluem a mídia impressa, a mídia falada e a eletrônica". Para Santaella (2000), mídias são meios, isto é, suportes materiais, canais físicos, nos quais as linguagens se corporificam e através dos quais transitam. Neste estudo o foco de investigação é a mídia impressa, isto é, o Jornal, em Umuarama/PR.

A mídia jornal, desde o seu surgimento, tem como referencial sua capacidade de transmitir notícias de forma direta. No contexto nacional, o advento do jornalismo data da primeira década do século XIX. A Gazeta do Rio de Janeiro foi o primeiro jornal impresso do Brasil e sua primeira veiculação foi em 10 de setembro de 1808 (RAMOS, 1985, p. 9). O primeiro jornal paranaense, Dezenove de Dezembro, de propriedade de Cândido Martins Lopes, circulou em $1^{\circ}$ de abril de 1854 até 1861, quando encerrou suas atividades por desentendimento político. (OLIVEIRA FILHA, p. 4). Ainda na esfera estadual, comparece Ponta Grossa cuja história do jornalismo começa com o surgimento do jornal Campos Geraes, de João Rocha Bahls, em 13 de maio de 1893. (PUZIO, 2012, p. 30).

Em Umuarama/PR, a atividade jornalística desponta já no início da década de 1960. O primeiro jornal, intitulado Gazeta de Umuarama, foi fundado por Lúcio Pipino (NASCIMENTO, 2009). Segundo registros contidos na primeira revista produzida em Umuarama/PR, "A Gazeta de Umuarama" (1965), foram constatadas informações sobre a origem da mídia jornal nessa cidade. A circulação do primeiro exemplar se deu em 26 de dezembro de 1961, e, inicialmente, era um jornal semanário. Para a sociedade umuaramense,

A Gazeta de Umuarama, o Jornal, e "A Gazeta de Umuarama”, a Revista em edição especial (1965), esses dois veículos representaram o marco inicial da mídia impressa, cada qual em sua modalidade de apresentação. 
Figura 1: Jornal - ed. 05 maio 1962

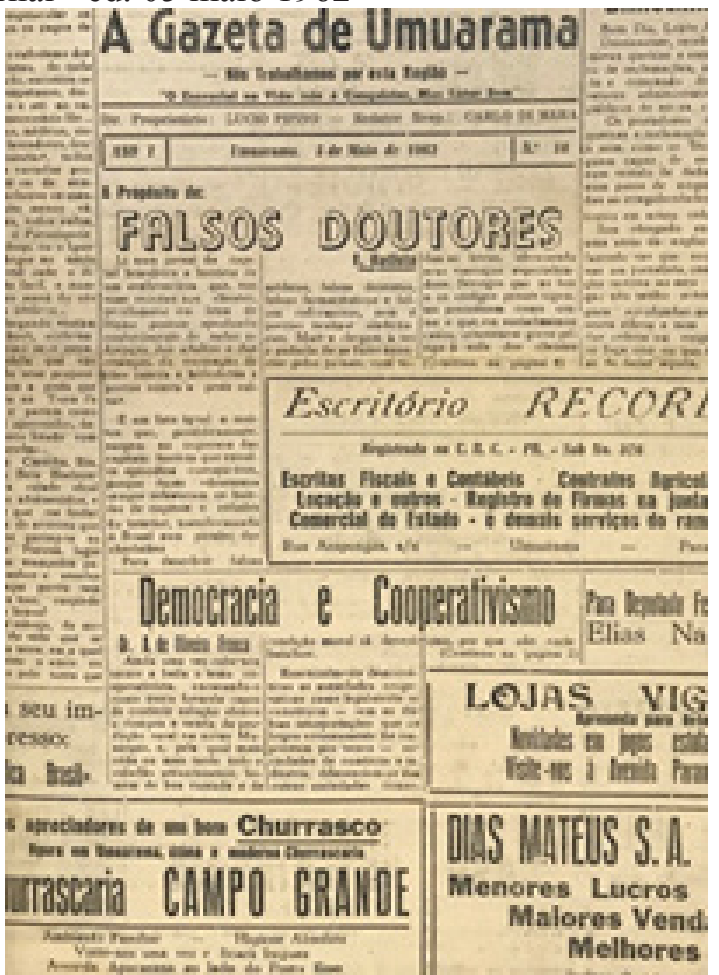

Fonte: os autores.

Figura 2: Primeira Revista - jun. 1965

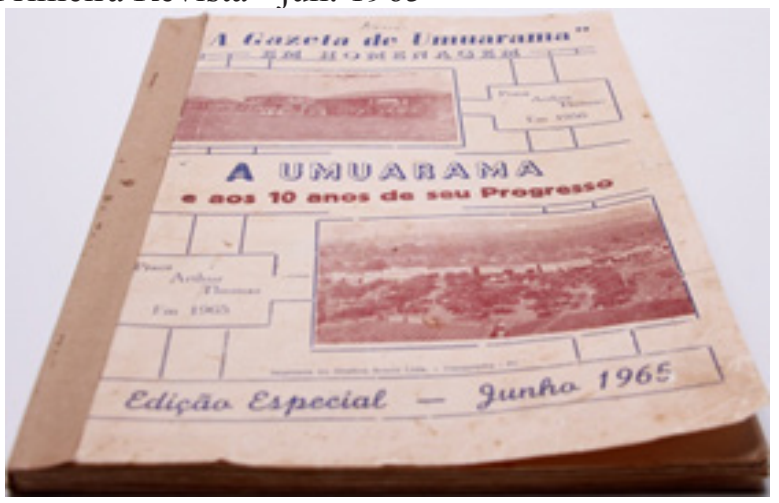

Fonte: os autores. 
Com o avanço tecnológico, a mídia impressa ganhou novos formatos. Houve uma simplificação dos métodos de produção da impressão que aproximaram jornais e revistas em termos de impressão (LEWIS; NELSON, 2001, p. 162). À medida que a técnica, em ambas as mídias, vai ficando mais sofisticada, novas opções vão surgindo tanto para os produtores de publicidade como para os anunciantes que podem contar com a eficácia visual nos resultados da comunicação de seus produtos, marcas e serviços. Grande é o número de publicidade veiculada nos jornais de Umuarama, tanto nos jornais diários quanto nos não diários.

Além dos jornais vigentes, a publicidade local ganhou novos espaços em outra mídia impressa, cuja origem está demarcada com uma publicação de junho de 1965: a Revista. Do mesmo produtor do jornal "A Gazeta de Umuarama", a revista comemorativa aos dez anos de fundação de Umuarama/PR foi veiculada naquele ano. Entre 1996 e 2015, foram produzidas e lançadas em Umuarama/PR dezenove novos títulos de revistas, em diferentes segmentos. (NASCIMENTO; OLIVA, 2011).

A partir da implantação da mídia impressa, na década de 1960, o universo publicitário começa a demarcar seu espaço, e conferir às marcas anunciantes nesse veículo de comunicação a projeção de suas imagens.

\section{AS EMPRESAS ANUNCIANTES NAS DÉCADAS DE 1960 E 1970 NO JORNAL A GAZETA DE UMUARAMA}

Com a implantação dessa primeira mídia impressa na cidade de Umuarama/PR, o jornal A Gazeta de Umuarama (1961), as empresas começaram a divulgar suas marcas. Moreira et al. (1996, p.196) definem a mídia jornal como "um meio impresso de comunicação e propaganda". O jornal A Gazeta de Umuarama se configurou, desde o início, nesse molde, como um meio de informação e publicidade.

O acervo do jornal "A Gazeta de Umuarama", foi doado à biblioteca da Universidade Paranaense - UNIPAR, pelo senhor Walter Sucupira. Em análise, verificou-se o número de empresas que divulgavam sua marca nesse jornal entre os anos de 1961 a 1975, ano este em que esse jornal foi extinto. Leduc et al (1977, p. 61) explicam que " a imprensa diária é uma das maiores mídias". A Gazeta de Umuarama se revelou uma mídia importante nesse período por sua exclusividade em Umuarama/PR, 
dividindo espaço apenas com o Rádio, uma mídia que foi implantada em 1962, a emissora Rádio Cultura.

De início, A Gazeta de Umuarama possuía entre quatro e cinco páginas de notícias e anúncios publicitários. No final dos anos 1960 e início de 1970, passou a apresentar dez páginas. Isso ocorreu devido ao aumento de notícias e também ao crescente número de anúncios. Segundo Rapp e Collins (apud COBRA, 1991, p.19), "a propaganda passa cada vez mais a ser utilizada para a conscientização, ajudando a posicionar o produto no mercado".

As empresas que anunciavam com mais frequência eram escritórios de advocacia e a rede Casas Buri. Com o aumento do número de empresas na cidade, também aumentaram os anúncios no jornal. Em 1962 eram em torno de 10 anúncios por edição. Já nos anos 1970, chegou a ser publicado até 34 anúncios por folha, sem considerar os anúncios de meia e de página inteira.

Os anunciantes da década de 1960 eram cerca de vinte prestadores de serviço, oito entre lojas de móveis e confecções, cinco empresas de peças para automóveis, sem incluir bares e fábricas que eram anunciantes assíduos. Na década de 1970, eram trinta e sete prestadores de serviço e cinquenta e cinco outros anunciantes de diversos segmentos que imprimiam sua marca nas páginas de A Gazeta de Umuarama.

Com a evolução da comunicação publicitária e o aumento da concorrência de mercado local, as empresas anunciantes tinham seus anúncios com cores e letras diferentes, acrescidos de imagens figurativas e fotografias. Com este estudo, verificou-se também que algumas empresas, como Casa Viga, Umuarama Diesel, Viação Umuarama, Autorama, Casa das Bombas, Supermercados Planalto, anunciantes entre 1968 e 1975, ainda se mantém em atividade na cidade de Umuarama/PR, enquanto a maioria delas foi extinta. E dessas empresas, a rede Supermercados Planalto continua anunciando nos jornais atuais.

Outro segmento anunciante nas décadas 1960 e 1970 era o de maquinários agrícolas. 


\section{ANUNCIANTES E ANÚNCIOS DE MÁQUINAS AGRÍCOLAS NO JORNAL A GAZETA DE UMUARAMA ENTRE OS ANOS DE 1960 A 1970}

Por meio de uma análise, foi possível identificar os anunciantes de máquinas agrícolas e o formato dos anúncios veiculados na primeira década de produção e circulação desse jornal em Umuarama/PR.

Segundo Ramos (1998, p. 25), o primeiro anúncio divulgado em jornal brasileiro data de 1808, com o surgimento da Gazeta do Rio de Janeiro. Nesse início, os anúncios seguiam o formato de classificados, e com a virada do século passou a dar lugar a anúncios com ilustração (CARRASCOZA, 1999, p. 76). Nos primeiros anos de produção, os anúncios de A Gazeta de Umuarama apresentavam imagens figurativas (ilustração). Em 1965 aparecem as primeiras imagens figurativas em preto em branco.

O primeiro anunciante no segmento de máquinas agrícolas foi Dausa S/A. Esta empresa já atuava na cidade de Umuarama/PR como distribuidora de automóveis das marcas Willis, Renault, Gordini, e passou a anunciar em quatro de abril de 1966 (ano V, n. 205, p. 4) a venda de tratores da marca Massey Fergusson. Contudo, desde a edição de 30 de janeiro de 1966 (ano V, n. 192, p, 7), foi veiculado um anúncio divulgando a breve inauguração da empresa Máquinas D'Andrea S/A, que entre seus produtos, máquinas de papéis e papelões, também comercializaria máquinas agrícolas, tais como: secadoras, beneficiadores, debulhadeiras, balões de ligas para café e demais grãos granulados, moinhos para ração e fubá, trituradores, máquinas para arroz e café.

O jornal A Gazeta de Umuarama foi um meio de comunicação propulsor na divulgação desses produtos, os maquinários agrícolas e suas respectivas marcas, bem como da marca de suas empresas revendedoras. Shimp (2002, p. 185) esclarece que marca é "a designação única de uma empresa, ou marca registrada, que distingue sua oferta dos outros produtos na mesma categoria".

Com o estudo verificou-se que, durante o período pesquisado, entre os anos de 1960 a 1970, duas foram as marcas anunciantes de máquina agrícolas no Jornal A Gazeta de Umuarama, Dausa e Máquinas D’Andrea $\mathrm{S} / \mathrm{A}$. Contudo, os anúncios dessa última empresa foram veiculados ape- 
nas no período de divulgação de sua futura inauguração, o que compreendeu de seis de fevereiro a 30 de abril de 1966. Já a empresa Dausa S/A anunciou de quatro de abril de 1966 a 15 de dezembro de 1968, portanto, foi anunciante por dois anos e oito meses.

Quanto aos aspectos gráficos dos anúncios, embora as imagens já fossem empregadas nos anúncios do jornal A Gazeta de Umuarama desde 1965, os anúncios das referidas empresas eram compostos em sua maioria por texto, enquanto alguns deles traziam imagens figurativas, isto é, as imagens não eram fotografias, mas sim ilustrações.

\section{A PUBLICIDADE NA MÍDIA IMPRESSA E SUA LINGUAGEM}

A publicidade na mídia impressa recebe o nome de anúncio. Interessante notar que, nas duas definições de anúncio que se seguem, explícita está a função a qual é inerente à publicidade, nesse tipo de material, o impresso.

Material persuasivo que é apresentado à massa como um apelo de uma entidade identificada; é geralmente pago e, portanto, completamente controlado no contexto, apresentação, veículo e tempo, pela entidade que emitiu o material (ANDRADE, 1978, p. 6).

Maneira através da qual o conteúdo de uma mensagem publicitária é apresentado, utilizando para isso os recursos de comunicação impressa ou eletrônica. Sua finalidade básica é informar, convencer, persuadir segmentos de públicos em relação a ideias, serviços ou produtos (MOREIRA et al. 1996, p. 32).

Deve-se assinalar que, para a produção de um anúncio, há recursos mais apropriados se considerados os objetivos a que se quer atingir. $\mathrm{O}$ anúncio impresso pode ser disposto em variados suportes materiais, isto é, qualquer material resultante de obras de impressão tipográfica. São jornais, revistas, panfletos, outdoors, folders, banners etc., cada qual com potencial comunicativo próprio, tanto na forma de apresentação da mensagem, quanto no modo de alcançar o consumidor-alvo. A escolha de um alvo, seja ele o consumidor ou o alvo da comunicação, está revelada, ora mais abertamente ora mais acanhadamente, na mensagem. Cabe, por ora, 
esclarecer a distinção entre consumidor-alvo e alvo de comunicação. Este é o público a que a mensagem deve chegar; aquele é o público a quem se deve vender.

Para Legrain e Magain (1992, p. 12), o alvo de comunicação é mais abrangente, porque deve alcançar a "todos os que intervêm no processo de compras e dirigir-se-á a cada um com uma pressão publicitária, de acordo com a importância de seu papel na decisão". Com o foco voltado a essa particularidade, ao alvo a ser alcançado, a mensagem se compõe com signos adequados. Cabral (1986) afirma que o conteúdo da mensagem publicitária deve corresponder ao nível do consumidor que vai decodificá-la. O produto deve ser apresentado de uma forma que ganhe vida, que se incorpore à vida do consumidor, satisfazendo suas necessidades objetivas e subjetivas. Estes são alguns aspectos da linguagem considerados nas análises da dinâmica discursiva dos anúncios publicitários impressos veiculados nos jornais.

Cabe enfatizar que toda produção discursiva deve estabelecer previamente o nível de comunicação a que se pretende alcançar. Para isso, parte da escolha dos elementos constitutivos da mensagem como também a definição do meio mais adequado de veiculação de uma peça publicitária. Meio e mensagem se amalgamam, visto que as linguagens constitutivas da mensagem se corporificam no meio, e este, como sustentáculo desse corpo, incorpora a mensagem. Lewis e Nelson (2001, p. 18), ao descreverem o objetivo da publicidade, enfatizam, sobretudo, os meios, ou seja, a atenção dada à escolha das mídias. Diante disso, pode-se dizer que a mensagem vem impressa à característica do meio.

São, portanto, no meio de comunicação jornal que este estudo se impõe analisar a evolução do discurso publicitário. O olhar investigativo dessa análise percorreu a linha do tempo para descrever as transformações, tanto na técnica de produção como no estilo discursivo, pelas quais o universo da comunicação publicitária na cidade de Umuarama/PR vem passando.

\section{O DISCURSO PUBLICITÁRIO E SUA EVOLUÇÃO NOS JOR- NAIS A GAZETA DE UMUARAMA E TRIBUNA DO POVO}

O discurso publicitário compreende uma mensagem com a fina- 
lidade de divulgar um produto, serviço ou marca, direcionada a um interlocutor. Para Carrascoza (1999, p.37), a produção discursiva "é fruto de uma cuidadosa pesquisa de palavras, vital na elaboração do texto de propaganda impressa".

Para a verificação da evolução do discurso publicitário, foi analisado o acervo de dois jornais impressos produzidos em Umuarama/PR: A Gazeta de Umuarama (1960-1975) e a Tribuna do Povo (1975-2007). Este estudo identificou a evolução do discurso publicitário ao longo de cinco décadas. Verificou-se que na década de 1960, o conteúdo discursivo centrava-se em apresentar apenas a empresa anunciante. Em se tratando de discurso publicitário, Mucchielli (1978, p. 50) explica que a mensagem publicitária deve despertar não somente o interesse, mas transformar o desejo latente em motivação de compra.

Embora, nos anúncios da década de 1960, a ênfase dada não fosse o produto, é notável que, nessa fase, a mensagem revelava a marca da empresa, que é também uma estratégia publicitária, ou seja, uma forma de fixar a marca, despertar no cliente o interesse, e logo levá-lo à ação. A ação, neste sentido, é o ato da aquisição do produto ou serviço.

Quanto à década de 1970, as imagens figurativas começaram a dividir o espaço publicitário com o conteúdo verbal. Segundo Molina (2007, p. 17), "o figurativo remonta à condição humana básica em expressar por figuras, cores e formas, os sentimentos, as críticas, as emoções”.

$\mathrm{Na}$ década de 1980, as imagens figurativas permaneceram nos anúncios, assim como a forma discursiva se manteve no mesmo estilo da década anterior.

O discurso publicitário começa então a se modificar na década de 1990. Os textos apresentam uma linguagem informal e a parte imagética se torna mais elaborada, isto é, estabelecendo com a mensagem verbal uma conexão de ideias, conferindo um caráter persuasivo à mensagem.

Nos anos 2000, a criatividade publicitária é valorizada por sua missão estética, tendo em vista prender a total atenção dos leitores pelo apelo visual. Segundo Carrascoza (1999, p. 105), quando a ilustração cedeu lugar à fotografia, "a linguagem da propaganda impressa atinge o status de uma arma persuasiva”. Os anúncios, nos anos que se seguiram, se revelaram predominantemente fixados pelo apelo visual, dando maior destaque às imagens e reduzindo o tamanho de textos. 


\section{APRESENTAÇÃO GRÁFICA DO ANÚNCIO PUBLICITÁRIO}

A composição gráfica de um anúncio impresso se faz a partir desta dupla de linguagem: a verbal e a visual. Do verbal, tomam-se emprestadas as palavras. Palavras tais que se vêm materializadas na iconicidade da escrita, a qual tende a atribuir-lhes múltiplas possibilidades de aparência, reveladas pelas propriedades da cor, da forma, da direção, do tipográfico, enfim de tudo que lhes pode conferir qualidades peculiares. Do visual, ainda, apodera-se da fotografia, das formas representativas e formas figurativas, atribuindo-lhes qualidades de aparências múltiplas, contando com toda a engenhosidade possível a partir de técnicas e estratégias na produção, e dos meios de veiculação.

Desde as primeiras edições do primeiro jornal produzido e veiculado em Umuarama/PR, A Gazeta de Umuarama, os anúncios publicitários dividiam o espaço com as notícias. Analisando o acervo dos jornais "A Gazeta de Umuarama" e "Tribuna do Povo", entre os anos de 1960 e 2000, notou-se a evolução dos anúncios publicitários. Este estudo focalizou os aspectos gráficos desses anúncios, no que se refere à tipografia, à cor e ao alinhamento estrutural.

Sobre a tipografia, Farias (1998, p.52) afirma que é a "peça-chave dentro do contexto do planejamento para um anúncio, pois ela contribui para delinear a personalidade de todo o conjunto dos elementos que o formam”. Verificou-se que entre as décadas de 1960 e 1970 os anúncios desses jornais não seguiam padrões gráficos, ou seja, havia variação entre uma produção e outra. De acordo com Ribeiro (1998, p. 27), "a escolha da fonte dentro de um projeto gráfico é de fundamental importância”.

Deve-se destacar que as imagens que acompanhavam os textos publicitários ainda eram pouco frequentes e apareciam na forma de ilustração, ou seja, imagens figurativas. As imagens fotográficas foram introduzidas no início de 1970. No decorrer do estudo, evidenciou-se que a cor foi introduzida no jornal "A Gazeta de Umuarama" em 1965, em uma edição de Natal. Apenas a capa apresentava um detalhe na cor verde, o que até então só era produzido nas cores preta e branca.

Em 1970 foi introduzida a cor vermelha para alguns detalhes do texto. Extinto em 1975, o jornal A Gazeta de Umuarama, cedeu lugar a dois outros jornais lançados em meados deste mesmo ano, Tribuna do 
Povo e Umuarama Ilustrado. Desses dois, este estudo analisou o primeiro. Neste o que mais se alterou, se comparado A Gazeta de Umuarama, foi a tipografia. Dos anos 1970 a 2000, são as tipografias com serifa. Segundo Damasceno (2003, p.79), "são as que se caracterizam pela presença de arremates nas partes superiores e inferiores das letras".

No decorrer das edições, foram constadas algumas variações de alinhamento estrutural do anúncio no jornal Tribuna do Povo, ocorridas até o final da década de 1980. A partir daí manteve-se um padrão em relação aos três aspectos analisados, tipografia, cor e alinhamento.

\section{CONCLUSÃO}

Com o propósito de identificar e compreender a evolução pela qual passou, e passa, o universo comunicacional de Umuarama/PR, desde a década de 1960, especificamente no que tange à linguagem da comunicação publicitária impressa veiculada em jornais locais, este estudo realizou uma análise da dinâmica discursiva da comunicação publicitária na mídia impressa.

Este estudo concluiu que, em aproximadamente cinco décadas (1960 a 2007), os anúncios publicitários veiculados nos jornais impressos A Gazeta de Umuarama e a Tribuna do Povo, do ponto de vista discursivo, isto é, da combinação texto e imagem, e também da técnica, passou por transformações em sua dinâmica de produção. Em seus primórdios, o discurso apresentava apenas a parte textual, sendo esta com ênfase na marca; vindo depois a acrescentar imagens figurativas; e a partir dos anos 1990, incluindo textos mais elaborados e imagens fotográficas.

Quanto aos aspectos que envolvem a técnica, este estudo verificou que, diante da evolução tecnológica ocorrida no período estudado, de 1960 a 2007, também houve avanços na forma de apresentação gráfica dos anúncios veiculados na mídia impressa de Umuarama/PR. Os anúncios publicitários são produzidos por agências de publicidade, sendo a maior parte delas instaladas em Umuarama/PR.

Verifica-se, ainda, que o nível gráfico dos anúncios saltou-se dos simples e econômicos enunciados apenas verbais, de 1965, aos estilos cartões de visita dos anos 1990, para um material mais elaborado, nesses últimos anos, que adotam as técnicas e as ferramentas mais modernas de 
que dispõem.

A evolução das máquinas possibilitou o emprego de novas técnicas de criação desse material. O resultado dessa produção, no meio jornal e também para as outras mídias impressas, se revela potencialmente comunicativo e eficaz na transmissão da mensagem publicitária, devido à utilização planejada de elementos gráficos, como a tipografia, a cor e a estrutura gráfica. Foi um salto, do mecânico, para o automatizado e até chegar ao digital. O mercado da comunicação impressa em Umuarama/ PR tem acompanhado essa evolução.

Recuperar as origens da comunicação impressa veiculadas em Umuarama/PR e registrar sua evolução significa não só trazer à luz parte da memória e a faceta da indústria publicitária como também revelar aspectos do desenvolvimento local e regional a partir do potencial que a publicidade impõe pela sua configuração na multiplicidade de sua dinâmica discursiva.

\section{REFERÊNCIAS}

\section{ANDRADE, C. T. Dicionário profissional de relações públicas e comunicação. São Paulo: Saraiva, 1978.}

CABRAL, P. Do outro lado do muro: propaganda para quem paga a conta. São Paulo: Summus, 1986.

CARRASCOZA, J.A. A evolução do texto publicitário. São Paulo: Futura, 1999.

COBRA, M. O impacto da propaganda: um estudo para algumas classes de bens. São Paulo. Atlas, 1991.

DAMASCENO, A. Webdesign: teoria e prática. Florianópolis: Visual Books, 2003.

FARIAS, L. Tipografia digital: o impacto das novas tecnologias. Rio de Janeiro: 2AB, 1998.

LEDUC, R. et al.Propaganda: uma força a serviço da empresa. São 
Paulo. Atlas, 1977.

LEGRAIN, M.; MAGAIN, D. Publicidade e propaganda. São Paulo: Makron Books, 1992.

LEWIS, H. G.; NELSON, C. Advertising age: manual de publicidade. São Paulo: Nobel, 2001.

MOLINA, A. L. Ensino de história e imagens: possibilidades de pesquisa. Domínios da Imagem, Londrina, ano I, n. I, p. 15-29, nov. 2007. Disponível em: <file://E:/S\%C3\%B4nia/Downloads/13-48-1-PB. pdf>. Acesso em: 10 ago. 2014.

MOREIRA, J. C. T. et al. Dicionário de termos de marketing. São Paulo: Atlas, 1996.

MUCCHIELLI, R. Psicologia da publicidade e da propaganda. Rio de Janeiro: LTC, 1978.

NASCIMENTO, S. M. M. A evolução da indústria da comunicação e seus meios de produção em Umuarama/PR. Revista de Ciências Empresariais da UNIPAR, Umuarama, v. 10, n. 2, jul./dez. 2009. p. 269-290.

NASCIMENTO, S. M. M.; OLIVA, R. A mídia revista em Umuarama/ PR: memória e Publicidade. Akrópolis - Revista das Ciências Humanas da UNIPAR, Umuarama, v. 19, n. 1, jan./mar. 2011, p. 5770.

OLIVEIRA FILHA, E. A. Apontamentos sobre a história de dois jornais curitibanos: "Gazeta do Povo" e "O Estado do Paraná". Cadernos da Escola de Comunicação UNIBRASIL. N. 2, jan./dez. 2004. Disponível em: <http://revistas.unibrasil.com.br/cadernoscomunicacao/ index.php/comunicacao/article/view/19/19>. Acesso em: 21 nov. 2014.

PUZIO, M. Por entre as colunas políticas: as representações das eleições municipais na imprensa escrita em Ponta Grossa - 1992 1996/2000. 140 f. Dissertação (Mestrado) - Universidade Estadual de 
Ponta Grossa, 2012. Disponível em: <http://www.bicen-tede.uepg.br/ tde_busca/arquivo.php?codArquivo=793>. Acesso em: 22 ago. 2014. RAMOS, R. Propaganda. São Paulo: Global, 1998.

. Do reclame à comunicação. São Paulo: Global, 1985.

RIBEIRO, M. Planejamento visual gráfico. Brasília: Linha Gráfica, 1998.

SANTAELLA, L. Cultura das mídias. São Paulo: Experimento, 2000.

SHIMP, T. A. Propaganda e promoção: aspectos complementares da comunicação integrada de marketing. Porto Alegre: Bookman, 2002.

ZANOTTO, A. F.; RIBEIRO, R. P. A História da Propaganda na Região de Umuarama, Noroeste do Paraná. In: QUEIROZ, A. (org.). Propaganda, História e Modernidade. Piracicaba: Degaspari, 2005. 